\title{
A measurement of decreasing impatience for health and money
}

\author{
Han Bleichrodt ${ }^{1} \cdot$ Yu Gao ${ }^{2}$ - Kirsten I. M. Rohde ${ }^{1}$ \\ Published online: 10 September 2016 \\ (C) The Author(s) 2016. This article is published with open access at Springerlink.com
}

\begin{abstract}
This paper measures deviations from constant discounting and compares these deviations for health and money. Our measurements make no assumptions about utility and do not require separability of preferences over time. In an experiment, most subjects were decreasingly impatient, but a substantial minority was increasingly impatient. The deviations from constant discounting were more pronounced for health than for money suggesting that time preferences are domain-specific. Hyperbolic discounting (Loewenstein and Prelec, Quarterly Journal of Economics, 107, 573-597, 1992) and proportional discounting (Mazur, Quantitative Analyses of Behavior, 5, 5573, 1987) best described time preferences. Quasi-hyperbolic discounting, the most popular model to accommodate deviations from constant discounting, was rejected for both health and money.
\end{abstract}

Keywords Time preference $\cdot$ Decreasing impatience $\cdot$ Hyperbolic discounting $\cdot$ Health

JEL Classifications $\mathrm{D} 91 \cdot \mathrm{I} 10$

Electronic supplementary material The online version of this article (doi:10.1007/s11166-016-9240-0) contains supplementary material, which is available to authorized users.

Han Bleichrodt

bleichrodt@ese.eur.nl

Yu Gao

yu.gao@polimi.it

Kirsten I. M. Rohde

rohde@ese.eur.nl

1 Erasmus School of Economics, PO Box 1738, 3000 DR Rotterdam, The Netherlands

2 Polytechnic University of Milan, Via Lambruschini 4/b, Milano, Italy 


\section{Introduction}

Private and policy decisions often involve outcomes that occur at different points in time. Some examples include choosing a pension plan and funding a screening program that reduces future illness. To account for their differences in timing, outcomes are usually discounted at a constant rate.

Constant discounting is tractable and has normative appeal, but it is inconsistent with observed behavior. Empirical evidence shows that discount rates typically decrease over time (Frederick et al. 2002; Attema 2012). Most evidence for decreasing impatience comes from studies using money outcomes, but it has also been observed for other domains such as health and environmental outcomes (Bleichrodt and Johannesson 2001; Van der Pol and Cairns 2011; van der Pol and Cairns 2002; Khwaja et al. 2007; Hardisty and Weber 2009; Cairns and Van der Pol 1997).

The violations of constant discounting have implications for policy. From Strotz (1955), we know that a decision maker who deviates from constant discounting may be prone to behave inconsistently over time and may have self-control problems, which lead to self-harming behaviors such as saving too little, addiction (Gruber and Köszegi 2001) and obesity (Scharff 2009; Ikeda et al. 2010). These self-control problems, in turn, may increase the welfare benefits from policy. For example, the net benefit of an increased tax on smoking may be much larger when the smoker does not discount at a constant rate, because the tax can serve as a commitment device that reduces the smoker's self-control problems and which he, therefore, values (Gruber and Köszegi 2004).

To assess the severity of departure from constant impatience, and, consequently, the vulnerability to self-control problems and the potential benefits from policy, the degree of decreasing impatience must be quantified. This is the aim of our paper.

Prelec (2004) showed that decreasing impatience cannot be quantified by looking at the speed of decline of discount rates. Hence, the abovementioned studies that found support for decreasing impatience and compared discount rates cannot be used to quantify decreasing impatience. Prelec argued that decreasing impatience should be measured by the Pratt-Arrow convexity of the logarithm of the discount function. Unfortunately, this measure is hard to observe empirically. Instead, we will use the method of Attema et al. (2010), which is informationally equivalent to Prelec's measure and can easily be applied empirically to measure the degree of decreasing impatience. Attema et al.'s measure makes no assumptions about utility or intertemporal separability. Existing studies on time preference generally imposed parametric assumptions on utility (most studies assumed linear utility) and assumed intertemporal separability. These assumptions cause distortions in the measurement of time preferences (Attema et al. 2012; Broome 1991; Loewenstein and Prelec 1993). Finally, Attema et al.'s method allows analyses at the individual level and, as we will show, individual time preferences are heterogeneous.

In an experiment, we compared deviations from constant discounting for money and health, two domains where economic analyses are widely used and discounting is routinely applied. Knowing whether time preferences are the same for health and money is important for both research and policy. Researchers often assume the same (constant) discounting of money and health and government offices try to set a single official discount rate to evaluate all public investments. If markets worked perfectly then this would be the appropriate discounting policy (Moore and Viscusi 1990). However, health is less transferable over time than money and there is no market for health to observe. In 
the presence of such market imperfections, it is unclear whether health and money should be discounted similarly. As noted by Moore and Viscusi (1990, p.52), this question must be resolved empirically, which is what the current paper seeks to do.

Several papers have compared discount rates for health and money. As mentioned above, the results from these studies cannot answer whether the degree of decreasing impatience differs between health and money, but they do shed light on whether people discount health and money similarly. The results are mixed (Attema 2012). While Moore and Viscusi (1990) and Cropper et al. (1994) found the same discounting for health and money, Cairns (1992) found more discounting for money and Cairns (1994) and Hardisty and Weber (2009) found more discounting for health gains and less for health losses. Moreover, the correlation between discounting for health and discounting for money is typically low (Chapman and Elstein 1995; Chapman 1996).

The empirical deficiencies of constant discounting have led to a variety of new discount models. The most widely-used of these is quasi-hyperbolic discounting (Phelps and Pollak 1968; Laibson 1997), which has become part of mainstream economics (Gruber and Köszegi 2001; Diamond and Köszegi 2003; DellaVigna 2009). Empirical evidence on the relative performance of these new discount models is thin on the ground, especially for health. This is unfortunate given the increasing use of these models in health (Gruber and Köszegi 2001; Gruber and Köszegi 2004; Newhouse 2006; Fang and Wang 2015). A final contribution of this paper is to present evidence about the descriptive validity of discount models.

Our results indicate that most subjects deviated from constant discounting and were decreasingly impatient for both money and health. Between 25\% (for health) and 35\% (for money) of our subjects behaved according to increasing impatience, a finding that most discount models cannot explain. Subjects deviated more from constant discounting for health than for money. This domain-dependence of discounting suggests that evidence on time preferences for money has only limited validity for health. Of the discounting models that we explored, hyperbolic discounting (Loewenstein and Prelec 1992) and proportional discounting (Mazur 1987) described time preferences for health and money best. Quasi-hyperbolic discounting and constant discounting could be rejected for both health and money.

\section{Background}

We consider a decision maker's preferences $\succcurlyeq$ over timed outcomes $(x, t)$, which denotes "receiving outcome $x$ at time $t$ ". Outcomes are health states or money amounts in our experiment. Time point $t=0$ is the present. We denote strict preference by $\succ$, indifference by $\sim$, and reversed preferences by $\preccurlyeq$ (weak reversed preference) and $\prec$ (strict reversed preference). Throughout the paper, we assume that the decision maker evaluates timed outcomes using discounted utility:

$$
D U(x, t)=\varphi(t) U(x)
$$

In Eq. (1), $\varphi$ is a decreasing and positive discount function and $U$ is a real-valued utility function. Because $\varphi$ is decreasing, the decision maker is impatient and prefers to receive good outcomes sooner rather than later. We scale $\varphi$ such that $\varphi(0)=1$. Utility is 
defined relative to a neutral outcome which has the value 0 . For money the neutral outcome was receiving nothing, for health we selected a specific health state (chronic back pain) that we assigned the value 0 .

Constant impatience says that preferences between timed outcomes do not change if we delay them by a common constant: for all $\sigma>0,(x, s) \sim(y, t)$ with $0 \prec x \prec y$ and $s<t$ implies $(x, s+\sigma) \sim(y, t+\sigma)$. Koopmans (1960) showed that constant impatience implies constant discounting: $\varphi(t)=\delta^{t}$ for $0<\delta<1$. Decreasing impatience holds if adding a common delay makes people more willing to wait for the better outcome: for all $\sigma>0,(x, s) \sim(y, t)$ with $0 \prec x \prec y$ and $s<t$ implies $(x, s+\sigma) \preccurlyeq(y, t+\sigma)$. Empirical studies have often found decreasing impatience, for both money (Frederick et al. 2002) and health (Attema 2012). Increasing impatience is the opposite of decreasing impatience and means that adding a common delay makes people less willing to wait for a larger outcome: for all $\sigma>0,(x, s) \sim(y, t)$ with $0 \prec x \prec y$ and $s<t$ implies $(x, s+\sigma) \succcurlyeq(y, t+\sigma)$. Several studies have found increasing impatience for money (e.g. Attema et al. 2010; Sayman and Öncüler 2009; Scholten and Read 2006; Loewenstein 1987; Takeuchi 2011). For health, only indirect evidence of increasing impatience exists (Attema et al. 2012).

Let $\succcurlyeq_{a}$ and $\succcurlyeq_{b}$ be the preference relations over timed outcomes of decision makers $a$ and $b$. We say that $\succcurlyeq_{b}$ is more decreasingly impatient than $\succcurlyeq_{a}$ if for all $0 \leq s<t$, for all $\varepsilon$, and for all outcomes $0 \prec_{a} x \prec_{a} y, 0 \prec_{b} x^{\prime} \prec_{b} y^{\prime}$, if $(x, s) \sim_{a}(y, t),(x, s+\sigma) \sim_{a}(y, t+$ $\sigma+\varepsilon)$ and $\left(x^{\prime}, s\right) \sim_{b}\left(y^{\prime}, t\right)$ then $\left(x^{\prime}, s+\sigma\right) \prec_{b}\left(y^{\prime}, t+\sigma+\varepsilon\right)$. Intuitively, if both $a$ and $b$ are willing to wait from period $s$ to period $t$ to receive a larger outcome ( $y$ instead of $x$ for decision maker $a$ and $y^{\prime}$ instead of $x^{\prime}$ for decision maker $b$ ), they are equally impatient for these outcomes and periods. Now, if $a$ is also willing to wait from period $s+\sigma$ to period $t+\sigma+\varepsilon$ to receive $y$ instead of $x$ then $b$ will prefer the larger later outcome $\left(y^{\prime}, t+\sigma+\varepsilon\right)$, because his impatience decreases faster than that of $a$ and, thus, he becomes more future-oriented than $a$.

Analogously, $\succcurlyeq_{b}$ is more increasingly impatient than $\succcurlyeq_{a}$ if for all $0 \leq s<t$, for all $\sigma>0$, for all $\varepsilon$, and for all outcomes $0 \prec_{a} x \prec_{a} y, 0 \prec_{b} x^{\prime} \prec_{b} y^{\prime}$, if $(x, s) \sim_{a}(y, t),(x, s+\sigma) \sim_{a}(y, t+$ $\sigma+\varepsilon)$ and $\left(x^{\prime}, s\right) \sim_{b}\left(y^{\prime}, t\right)$ then $\left(x^{\prime}, s+\sigma\right) \succ_{b}\left(y^{\prime}, t+\sigma+\varepsilon\right)$.

Various alternative models have been proposed to accommodate the deviations from constant discounting. The most popular of these models is quasi-hyperbolic discounting (Phelps and Pollak 1968; Laibson 1997):

$$
\varphi(t)= \begin{cases}\beta \delta^{t} & \text { for } t>0 \\ 1 & \text { for } t=0\end{cases}
$$

with $0<\beta, \delta<1$. Quasi-hyperbolic discounting differs from constant discounting only in the first period. The model assumes that a decision maker gives extra weight to the present and the parameter $\beta$ captures this present bias. Present bias leads to decreasing impatience in the first period and constant impatience in all later periods.

Loewenstein and Prelec (1992) proposed a more general model, hyperbolic discounting, in which decreasing impatience not only occurs in the first period but also in later periods:

$$
\varphi(t)=(1+h t)^{-\frac{r}{h}}, h \geq 0, r>0
$$


The parameter $h$ measures decreasing impatience. If $h=0$ then hyperbolic discounting is equivalent to constant discounting and the larger $h$ is, the more the decision maker deviates from constant discounting. Two special cases of hyperbolic discounting are proportional discounting (Mazur 1987), which results from Eq. (3) when $h=r$ and power discounting (Harvey 1986), which results when $h=1$.

For money, Abdellaoui et al. (2010, 2013) concluded that hyperbolic discounting performed better than constant, quasi-hyperbolic, proportional, and power discounting, even after correction for the differences in degrees of freedom. For health, van der Pol and Cairns (2002) found some evidence that hyperbolic discounting and power discounting fitted better than constant discounting and proportional discounting. Bleichrodt and Johannesson (2001) and Van der Pol and Cairns (2011) found that hyperbolic discounting fitted better than constant discounting and quasi-hyperbolic discounting for health.

\section{Time trade-off sequences}

Because deviations from constant impatience are closely related to economic and health misbehaviors, it is of interest to measure these deviations. ${ }^{1}$ Prelec (2004) argued that deviations from constant impatience should be measured by the Pratt-Arrow convexity of the logarithm of the discount function: $-\ln (\varphi)^{\prime \prime} / \ln (\varphi)^{\prime}$. This measure is hard to observe empirically. First, we must measure the discount function, which is complex because discounting and utility interact, then we must take the logarithm, and, finally, we must compute first and second derivatives.

Attema et al. (2010) showed that deviations from constant impatience can be measured more easily using time trade-off sequences. To illustrate, we first choose two outcomes $x$ and $y$ with $x \prec y$. A time trade-off sequence is a sequence of time points $t_{0}, t_{1}, \ldots, t_{k}$ such that

$$
\begin{gathered}
\left(x, t_{0}\right) \sim\left(y, t_{1}\right) \\
\left(x, t_{1}\right) \sim\left(y, t_{2}\right) \\
\vdots \\
\left(x, t_{k-1}\right) \sim\left(y, t_{k}\right)
\end{gathered}
$$

We call $W T W_{i}=t_{i}-t_{i-1}, i=1, \ldots, k$, the decision maker's willingness to wait (WTW). Constant impatience implies that the willingness to wait is constant, decreasing impatience implies that the willingness to wait increases with $i$, and increasing impatience implies that the willingness to wait decreases with $i$. From Eq. (1), we obtain

$$
\varphi\left(t_{0}\right) / \varphi\left(t_{1}\right)=\varphi\left(t_{1}\right) / \varphi\left(t_{2}\right)=\cdots=\varphi\left(t_{k-1}\right) / \varphi\left(t_{k}\right)
$$

\footnotetext{
${ }^{1}$ Strictly speaking, violations of constant impatience are not equivalent to time inconsistent behavior (reversals of preference over time) and self-control problems (Harvey 1995). However, they are equivalent under the common assumption of time invariance (Halevy 2015).
} 
This is equivalent to:

$$
\ln \left(\varphi\left(t_{0}\right)\right)-\ln \left(\varphi\left(t_{1}\right)\right)=\ln \left(\varphi\left(t_{1}\right)\right)-\ln \left(\varphi\left(t_{2}\right)\right)=\cdots=\ln \left(\varphi\left(t_{k-1}\right)\right)-\ln \left(\varphi\left(t_{k}\right)\right)
$$

Eq. (6) shows that a time trade-off sequence is equally spaced in terms of $\ln (\varphi)$. This property does not depend on utility. Utility drops from Eqs. (5) and (6) and we do not have to make any assumptions about it.

We now define the time curve

$$
\tau(t)=\frac{\ln (\varphi(t))-\ln \left(\varphi\left(t_{k}\right)\right)}{\ln \left(\varphi\left(t_{0}\right)\right)-\ln \left(\varphi\left(t_{k}\right)\right)}
$$

From Eq. (7), $\tau\left(t_{0}\right)=1, \tau\left(t_{k}\right)=0$, and $\tau\left(t_{j}\right)=1-j / k$. Because $\tau\left(t_{j}\right)=1-j / k$, the elements of the time trade-off sequence are also equally spaced in terms of $\tau$. Under constant discounting $\tau$ is linear, under decreasing impatience it is convex, and under increasing impatience it is concave. Attema et al. (2010) showed that $\tau$ has the same degree of convexity as $\ln (\varphi)$ : $-\frac{\tau^{\prime \prime}}{\tau^{\prime}}=-\frac{\ln (\varphi)^{\prime \prime}}{\ln (\varphi)^{\prime}}$. In other words, $\tau$ can be used instead of $\ln (\varphi)$ to measure decreasing impatience and decision maker $a$ is more decreasingly impatient than decision maker $b$ if $a$ 's time curve is more convex than $b$ 's time curve. The big advantage of using $\tau$ instead of $\ln (\varphi)$ is that $\tau$ is directly observable whereas $\ln (\varphi)$ is not.

The time curve can also be used to test the different discount models. Rohde (2010) proposed the hyperbolic factor:

$$
\operatorname{hyp}(i, j)=\frac{\left(t_{j}-t_{i}\right)-\left(t_{j-1}-t_{i-1}\right)}{t_{i}\left(t_{j-1}-t_{i-1}\right)-t_{i-1}\left(t_{j}-t_{i}\right)}
$$

with $t_{i}<t_{j}$. and derived that:

Observation 1 (Rohde 2010): The hyperbolic factor is:

1. Equal to zero under constant discounting,

2. Positive if $t_{i-1}=0$ and zero if $t_{i-1}>0$ under quasi-hyperbolic discounting,

3. Equal to $h>0$ under hyperbolic discounting. Moreover, under hyperbolic discounting the denominator of Eq. (8) should be positive,

4. Equal to $r$ under proportional discounting, and

5. Equal to 1 under power discounting.

\section{Experiment}

Our experiment elicited time trade-off sequences for health and money. We recruited 75 students (36 female) from Erasmus University Rotterdam, mainly from economics and business. Every subject received a $€ 12$ participation fee. The experiment was computerrun in 14 small group sessions. Subjects were seated in cubicles and could not see each other's screens or interact. 
The experiment consisted of two parts, the elicitation of the time trade-off sequences for health and for money. We randomized the order of these parts. Each part started with instructions and four comprehension questions (see the Online Appendix). After a subject had correctly answered all four comprehension questions, he answered two training questions. We told subjects that the training questions and the experimental questions had no right or wrong answers and that we were only interested in their preferences. Subjects were encouraged to ask questions at any time they wished should something be unclear.

We measured four time trade-off sequences for each subject, two for health and two for money. Table 1 shows the stimuli. All delays were in weeks. For both health and money, one sequence started immediately and the other in 4 weeks. We randomized which of these sequences came first.

For money we used $x=€ 500$ and $y=€ 550$ to elicit the time trade-off sequences. For health, we told subjects to imagine that they suffered from chronic back pain (the neutral level). Chronic back pain was described as:

- You have moderate problems in walking about.

- You have moderate problems performing your usual activities

(e.g., work, study, housework, family or leisure activities).

- You have moderate pain or discomfort.

We told subjects that there are two treatments (A and B) to relieve chronic back pain. Table 2 shows the descriptions of the two treatments, which were presented to subjects on their computer screens. For easy reference, they were also printed on cards, which we put on subjects' desks. Treatment B was more effective than Treatment A. Both treatments removed the pain, but B also improved walking and the performance of usual activities. The effects of the treatments started immediately at the beginning of the treatment and lasted for exactly one week, the unit of time we use in this paper. After this week, chronic back pain returned. Such questions are common in the measurement of time preferences for health (e.g. Van der Pol and Cairns 2011; Hardisty and Weber 2009) except that subjects usually consider only one change in health (e.g. Treatment A) and the duration of this change is varied. There are two advantages of keeping the duration of change fixed. First, the utility for time duration can be entirely general. Studies that vary the duration of change have to impose simplifying assumptions on the utility for time duration to be able to analyze the responses and most studies assume it is linear. A second advantage of keeping the duration of change fixed is that subjects will more

Table 1 Stimuli of the four sequences

\begin{tabular}{lllll}
\hline Parts & Sequence & $\mathrm{t}_{0}$ & $\mathrm{x}$ & $\mathrm{y}$ \\
\hline Health & H1 & Immediately & Treatment A & Treatment B \\
& H2 & 4 weeks & Treatment A & Treatment B \\
Money & M1 & Immediately & 500 euro & 550 euro \\
& M2 & 4 weeks & 500 euro & 550 euro \\
\hline
\end{tabular}


Table 2 The descriptions of the treatments

Treatment A

During one week

- You have moderate problems in walking about.

- You have moderate problems with performing your usual activities

(e.g. work, study, housework, family or leisure activities).

- You have no pain or discomfort.
Treatment B

During one week

- You have slight problems in walking about.

- You have no problem with performing your usual activities

(e.g. work, study, housework, family or leisure activities)

- You have no pain or discomfort.

likely concentrate on the time point at which the change occurs, which is desirable as we are interested in the properties of the discount function and not in those of the utility function.

Our instructions told subjects to adopt chronic back pain as their neutral level of health. Because most subjects were healthy, chronic back pain could have been perceived as a loss and not as neutral. However, empirical evidence suggests that the reference point or neutral level of health can be manipulated and even healthy subjects usually adopt a health state which is worse than their current health if instructed to do so (Bleichrodt and Pinto 2002; Attema et al. 2013; van Osch et al. 2006).

Each sequence consisted of four elements $(k=4)$. All indifferences were elicited using a series of choices. This procedure is common in experimental economics, because it leads to fewer inconsistencies than directly asking subjects for their indifference values (Bostic et al. 1990). We will describe the choice-based elicitation procedure for health. It was similar for money with $€ 500$ instead of Treatment A and with $€ 550$ instead of Treatment B.

Subjects first made several pairwise choices. These choices limited the range within which their willingness to wait fell. Figure 1 gives an example of a pairwise choice for health.

In the first pairwise choice, the benefits of Treatment B occurred in 100 weeks. The next choices then zoomed in on subjects' willingness to wait. Once the range within which their willingness to wait fell had been narrowed to at most 13 weeks, subjects filled out a choice list. Figure 2 gives an example. The first and final choice on the list had been made before. So in Fig. 2 the subject had already chosen B in 12 weeks over A immediately and A immediately over B in 25 weeks. Consistency requires that a subject switches from B to A at some choice in the list. If the subject always chose the same treatment then the elicitation would recommence for this question starting with the first pairwise choice. If the subject was also inconsistent in the repeated elicitation then we treated the response to this question as missing. There were six subjects who never switched in at least one choice list.

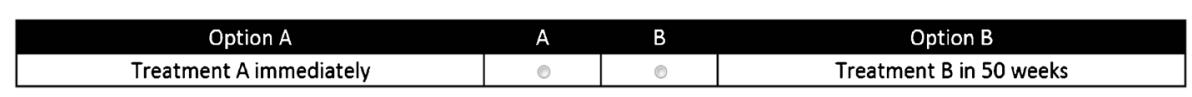

Fig. 1 An example of a pairwise choice for health 


\begin{tabular}{|c|c|c|c|}
\hline Option A & A & B & Option B \\
\hline \multirow{14}{*}{ Treatment A immediately } & 0 & 0 & Treatment B in 12 weeks \\
\hline & 0 & 8 & Treatment B in 13 weeks \\
\hline & 0 & 0 & Treatment B in 14 weeks \\
\hline & 0 & $\theta$ & Treatment B in 15 weeks \\
\hline & $\theta$ & 0 & Treatment B in 16 weeks \\
\hline & 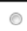 & 0 & Treatment B in 17 weeks \\
\hline & 0 & 0 & Treatment $\mathrm{B}$ in 18 weeks \\
\hline & 0 & 0 & Treatment B in 19 weeks \\
\hline & 0 & 0 & Treatment B in 20 weeks \\
\hline & 0 & 0 & Treatment B in 21 weeks \\
\hline & 0 & 0 & Treatment B in 22 weeks \\
\hline & 0 & 0 & Treatment B in 23 weeks \\
\hline & 0 & 0 & Treatment B in 24 weeks \\
\hline & 0 & 0 & Treatment B in 25 weeks \\
\hline
\end{tabular}

Fig. 2 An example of a choice list for health

The upper bound for the delay in Option B was 500 weeks. If a subject still preferred $\mathrm{B}$ for a delay of 500 weeks, we also treated his response to this question as missing. Six subjects did this at least once. These subjects were the most patient. To test whether the exclusion of the most patient subjects biased the results, we repeated the individual analyses by also excluding the six most impatient subjects. This robustness check led to the same conclusions in all but one case and we will only report the single case where the results differed.

\section{Results}

We removed a subject's missing choices, but kept the other, completed, choices in the aggregate analyses. In the individual analyses, we needed all choices and the 12 subjects with missing data were removed. ${ }^{2}$ The individual analyses, therefore, used the responses of 63 subjects.

\subsection{Consistency}

For each subject we repeated two randomly selected elicitations, one for health and one for money to assess data quality. The consistency of the measurements was good. The original and the repeated measurements did not differ, neither for health (Wilcoxon test, $p=0.86$ ) nor for money (Wilcoxon test, $p=0.58$ ). The median absolute difference between the original and the repeated measurement was one week for both health and money.

\subsection{Aggregate results}

Figure 3 shows the four time curves based on the mean data. The figures based on the median data are similar. The dashed lines correspond to constant discounting. For health, Panels $\mathrm{A}$ and $\mathrm{B}$ show that the mean data deviated from constant discounting. The

\footnotetext{
${ }^{2}$ Six subjects never switched between Options A and B and eight were extremely patient. Two of the extremely patient subjects never switched either. Therefore we excluded 12 subjects in total.
} 

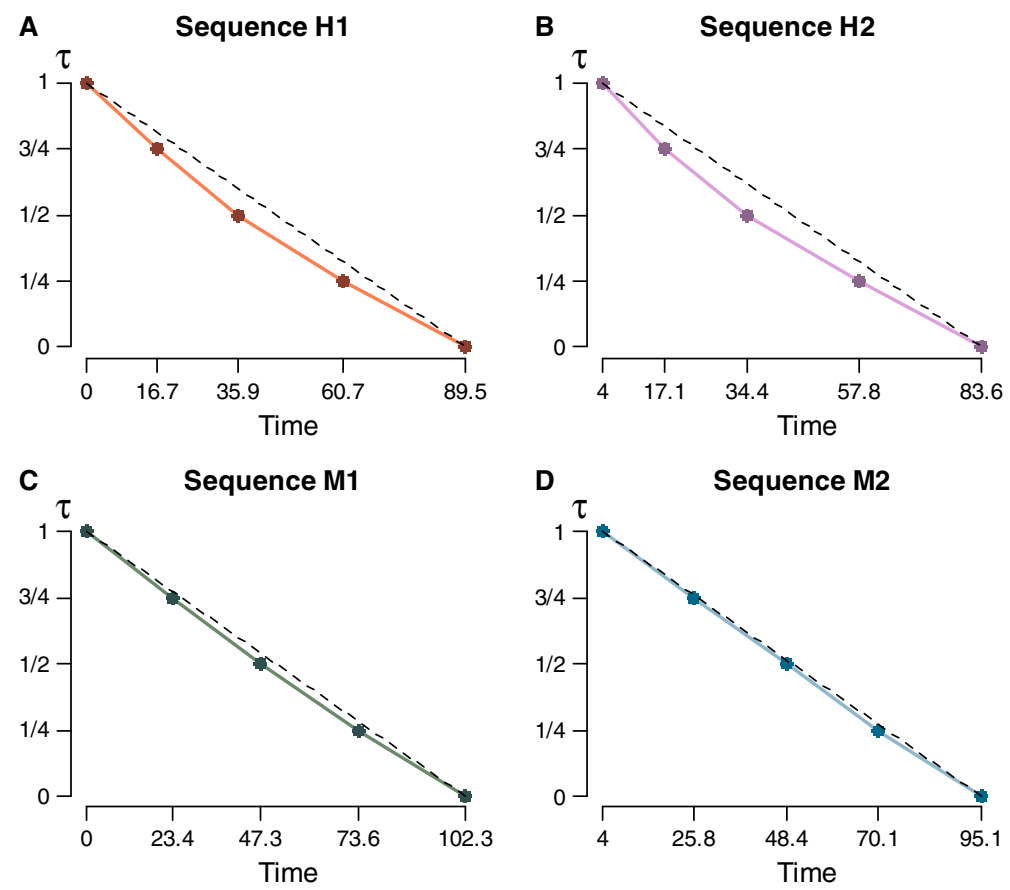

Fig. 3 The elicited time trade-off sequences using the mean data

convex shape of the time curves indicates that subjects were decreasingly impatient. ${ }^{3} \mathrm{We}$ could reject the null hypothesis of constant impatience against the alternative of decreasing impatience in both sequences (Page's L-test, both $p<0.01$ ).

The data are inconsistent with quasi-hyperbolic discounting, which predicts that violations of constant discounting only occur when the present (time point 0) is involved and, hence, not in sequence $\mathrm{H} 2$. We could also test quasi-hyperbolic discounting by removing the first observation (the present) from sequence H1. Then all health outcomes occur in the future and quasi-hyperbolic discounting predicts constant impatience. This prediction could also be rejected (Page's L-test, $p<0.01$ ).

Panels C and D in Fig. 3 show the time curves for the two money sequences M1 and M2. We could also reject constant impatience for money in favor of decreasing impatience (Page's L-test, both $p<0.01$ ). The rejection of constant impatience in sequence M2 also violates quasi-hyperbolic discounting. Moreover, we could also reject the prediction of quasi-hyperbolic discounting that constant impatience should hold in sequence M1 when the first observation is removed (Page's L-test, $p=0.01$ ).

Figure 3 suggests that the deviations from constant discounting were larger for health than for money. To test this conjecture, we fitted the time curves by an exponential function $\tau(t)=e^{-\alpha t}$, where $\alpha$ reflects the convexity of the time curve and, thus, the degree

\footnotetext{
${ }^{3}$ Decreasing impatience predicts that the WTW increases over the time trade-off sequence, which was largely confirmed. In the first health sequence (H1), the first and the second WTW were lower than the third and the fourth WTW (Wilcoxon test, all $p<0.01$ ), but the first WTW did not differ from the second WTW and the third WTW did not differ from the fourth WTW. In the second health sequence (H2) all predictions were confirmed (Wilcoxon test, $p=0.02$ in the comparison between the first and the second WTW, all other $p<0.01$ ) except that the third and the fourth WTW did not differ.
} 
of decreasing impatience- $-\frac{\tau^{\prime \prime}}{\tau^{\prime}}=-\frac{\ln (\varphi)^{\prime \prime}}{\ln (\varphi)^{\prime}}$. We used R (R Core Team 2013) and the nlme package (Pinheiro et al. 2014) to perform a nonlinear mixed-effects estimation of the exponential function with dummies to test for the fixed effects of outcome domain and the initial delay and subject as a random effect. $P$-values were obtained by likelihood ratio tests of the model with the dummy in question against the model without the dummy in question.

The exponential coefficients $\alpha$ were indeed larger for health than for money (LRtest, $p<0.01)$. We could not reject the null that the coefficients were the same for the two health sequences (LR-test, $p=0.47$ ), but for money the coefficient of sequence M2 exceeded that of sequence M1 (LR-test, $p<0.01$ ) signaling larger deviations from constant discounting in sequence M2. This finding, once again, contradicts quasihyperbolic discounting.

\subsection{Individual results}

The individual time curves showed much heterogeneity. To illustrate, Fig. 4 shows the time curves of four subjects for sequence H1. Subject 24 was clearly decreasingly impatient and Subject 10 was clearly increasingly impatient. The time curve of Subject 26 resembles quasi-hyperbolic discounting. His willingness to wait first increases,
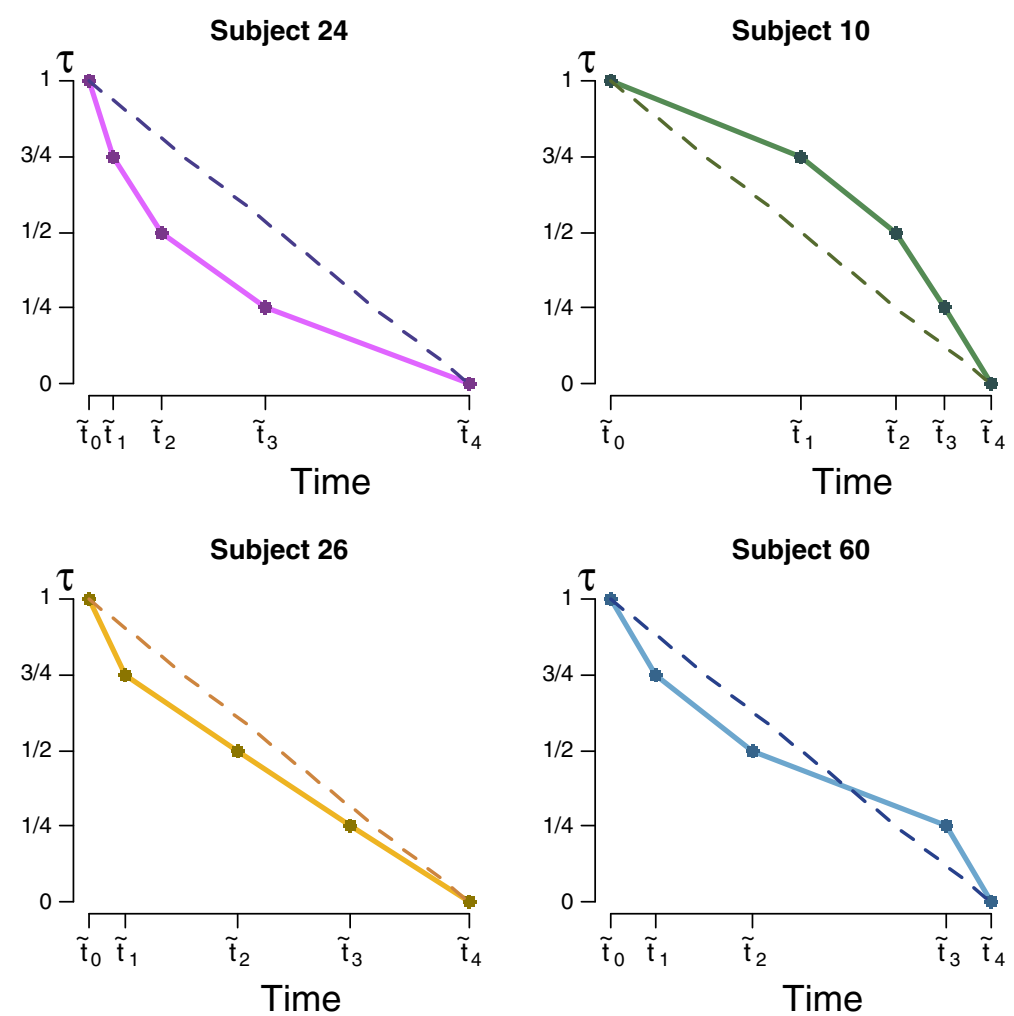

Fig. 4 Four different time curves 
which is consistent with decreasing impatience, and then remains constant. Finally, Subject 60 is first decreasingly impatient and then becomes increasingly impatient.

To quantify decreasing impatience, we computed for each subject a decreasing impatience (DI) index. The DI index measures the difference between the area under the diagonal and the area under the normalized time curve. ${ }^{4}$ It is positive for a decreasingly impatient subject, zero for a constantly impatient subject, and negative for an increasingly impatient subject. However, a subject with a zero DI index is not necessarily constantly impatient. Subject 60 is a case in point. His time curve crosses the diagonal and his DI index was close to zero, but he did not behave according to constant impatience. To capture such preferences, we also computed a non-stationarity (NS) index, which measures the deviation from constant impatience. ${ }^{5}$ The NS index is related to the absolute value of the difference between the area under the diagonal and the area under the normalized time curve. The larger this area, the more a subject deviated from constant discounting. The analysis based on the NS index mostly gave the same results and we only present the results when they differed from those based on the DI index.

Table 3 shows that in both health sequences a majority of the subjects were decreasingly impatient. Around $25 \%$ of the subjects (16 out of 63) were increasingly impatient. Impatience was a stable behavioral trait, as around $75 \%$ of the subjects displayed the same type of impatience in both sequences. Only 9 subjects switched from decreasing impatience in one sequence to increasing impatience in the other. These switching subjects were typically much more patient than non-switching subjects and, as a result, their willingness to wait was somewhat imprecise. For example, subject 5's H1 and H2 sequences were $(39,76,116,162)$ and $(37,81,123,156)$. These sequences suggest that subject 5 was willing to wait around 40 weeks for the improvement in health, but as he was patient, he did not care much whether he had to wait, say, 38 weeks or 42 weeks. As a result, his responses were a bit imprecise and we classified him as decreasingly impatient in the first sequence and as increasingly impatient in the second sequence.

Table 4 shows that decreasing impatience was also the most common pattern for the two money sequences, but that between $25 \%$ and $35 \%$ of the subjects were increasingly impatient. Impatience was less stable for money than for health, with 16 subjects switching from decreasing impatience in one sequence to increasing impatience in the other. As for health, switching subjects were on average much more patient than non-switching subjects and the switch from decreasing to increasing impatience (and vice versa) could be explained by preference imprecision. However, there were also some subjects for whom the switch was probably caused by errors. For example, subject 56's M1 and M2 sequences were $(4,8,12,15)$ and $(7,10,14,17)$. These responses could be explained as follows. In sequence M1 he was always willing to wait 4 weeks, but he made one error such that his final willingness to wait was only 3 weeks. In sequence M2 he was always willing to wait 3 weeks, but, again, he made

\footnotetext{
$\overline{{ }^{4} \text { The normalized values of } t_{i} \text { are: }} \widetilde{t_{i}}=\frac{t_{i}-t_{0}}{t_{4}-t_{0}}, i=1, \ldots, 4$. They lie between 0 and 1 . The normalization was necessary to compare the indices between subjects and to perform statistical tests. The values of $t_{i}$ differed across subjects and, ceteris paribus, larger values of $t_{i}$ led to larger differences between the areas under the diagonal and under the time curve. The DI index is defined as: $D I=\sum_{i=1}^{4}\left(\frac{i}{4}-\widetilde{t}_{i}\right)$.

${ }^{5}$ The NS index is defined as: $N S=\sum_{i=1}^{4}\left|\frac{i}{4}-\widetilde{t}_{i}\right|$.
} 
Table 3 Classification of subjects for health based on the decreasing impatience indices

\begin{tabular}{llllll}
\hline & & \multicolumn{2}{l}{ Sequence H2 } & & \\
\cline { 3 - 5 } & & $\begin{array}{l}\text { Decreasing } \\
\text { impatience }\end{array}$ & $\begin{array}{l}\text { Increasing } \\
\text { impatience }\end{array}$ & $\begin{array}{l}\text { Constant } \\
\text { impatience }\end{array}$ & Subtotal \\
\hline Sequence H1 & Decreasing impatience & 27 & 5 & 4 & 36 \\
& Increasing impatience & 4 & 10 & 2 & 16 \\
& Constant impatience & 1 & 1 & 9 & 11 \\
& Subtotal & 32 & 16 & 15 & Total: 63 \\
\hline
\end{tabular}

one error such that his third willingness to wait was 4 weeks. The consequence of these two small errors was that we classified him as increasingly impatient in sequence M1 and as decreasingly impatient in sequence M2 even though he, probably, was constantly impatient.

Figure 5 shows the DI indices for the two health sequences. Most points lie in the first quadrant and the mean DI index was significantly positive for both sequences (Wilcoxon test, both $p<0.01$ ) consistent with decreasing impatience for health. The DI indices of sequences $\mathrm{H} 1$ and $\mathrm{H} 2$ did not differ (Wilcoxon test, $p=0.54$ ). The correlation between the two DI indices was substantial $(\rho=0.62, p<0.01)$, suggesting that time preferences for health were relatively stable.

Figure 6 shows the DI indices for the two money sequences. The means of both sequences differed from 0 (Wilcoxon test, $p=0.04$ for sequence 3 and $p<0.01$ for sequence 4 ). The DI indices did not differ (Wilcoxon test, $p=0.38$ ), but their correlation was only fair $(\rho=0.25, p=0.05)$, suggesting that time preferences were less stable for money than for health.

Figure 7 shows the relation between the DI indices for health and money. Panels A and $\mathrm{D}$ show that the indices for health and the first money sequence were moderately correlated $(\rho=0.46(p<0.01)$ between sequences H1 and M1 and $\rho=0.48(p<0.01)$ between sequences H2 and M1). The correlations between the two health sequences and sequence M2 were much lower and only slight to fair $(\rho=0.27(p=0.04)$ between sequences H1 and M2 and $\rho=0.11(p=0.37)$ between sequences H2 and M2).

Table 4 Classification of subjects for money based on the decreasing impatience indices

\begin{tabular}{llllll}
\hline & \multicolumn{3}{c}{ Sequence M2 } & & \\
\cline { 3 - 5 } & & $\begin{array}{l}\text { Decreasing } \\
\text { impatience }\end{array}$ & $\begin{array}{c}\text { Increasing } \\
\text { impatience }\end{array}$ & $\begin{array}{l}\text { Constant } \\
\text { impatience }\end{array}$ & Subtotal \\
\hline Sequence M1 & Decreasing impatience & 22 & 6 & 2 & 30 \\
& Increasing impatience & 10 & 10 & 2 & 22 \\
& Constant impatience & 1 & 1 & 9 & 11 \\
& Subtotal & 33 & 17 & 13 & Total: 63 \\
\hline
\end{tabular}




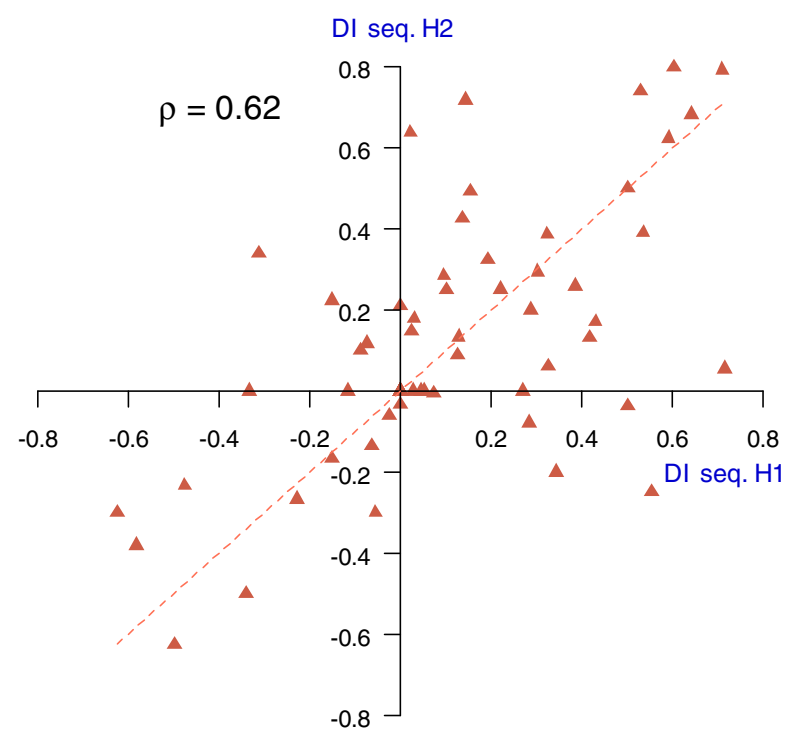

Fig. 5 DI indices for the two health sequences

The DI indices indicated more decreasing impatience for health than for money. However, this difference was only significant in the comparison with sequence M1. ${ }^{6}$ The NS indices showed greater deviations from constant impatience for health than for money in all comparisons. ${ }^{7}$ The finding that the DI and NS indices of sequences H2 and M2 differed significantly from zero provided further evidence against quasi-hyperbolic discounting.

\subsection{Hyperbolic factors}

So far, the analysis has shown that our subjects violated constant and quasi-hyperbolic discounting for both health and money. To gain additional insight into the validity of the different discount models, we computed hyperbolic factors for each subject. The hyperbolic factors are undefined when their denominator is negative, which happens when a subject is extremely decreasingly impatient. Such behavior cannot be accommodated by any of the hyperbolic alternatives for constant discounting and requires more general discount models (Ebert and Prelec 2007; Bleichrodt et al. 2009). It was rare in our data. For each subject, we computed 24 hyperbolic factors, 6 per sequence. In all sequences, less than $10 \%$ of the hyperbolic factors had a negative denominator (5\% in $\mathrm{H} 1$ and $\mathrm{M} 1,8 \%$ in $\mathrm{H} 2$ and $\mathrm{M} 2$ ).

We could not reject the null hypothesis of equal hyperbolic factors within each of the four sequences (Friedman test, all $p>0.09$ ). However, this result was sensitive to the

\footnotetext{
${ }^{6}$ Wilcoxon tests, $p=0.02$ in the comparison between sequences $\mathrm{H} 1$ and M1, $p=0.18$ in the comparison between $\mathrm{H} 1$ and $\mathrm{M} 2, p=0.03$ in the comparison between sequences $\mathrm{H} 2$ and $\mathrm{M} 1$, and $p=0.19$ in the comparison between sequences $\mathrm{H} 2$ and $\mathrm{M} 2$.

${ }^{7}$ Wilcoxon tests, $p=0.02$ in the comparison between sequences H1 and M1, $p=0.01$ in the comparison between $\mathrm{H} 1$ and $\mathrm{M} 2, p=0.06$ in the comparison between sequences $\mathrm{H} 2$ and $\mathrm{M} 1$, and $p=0.03$ in the comparison between sequences $\mathrm{H} 2$ and $\mathrm{M} 2$.
} 


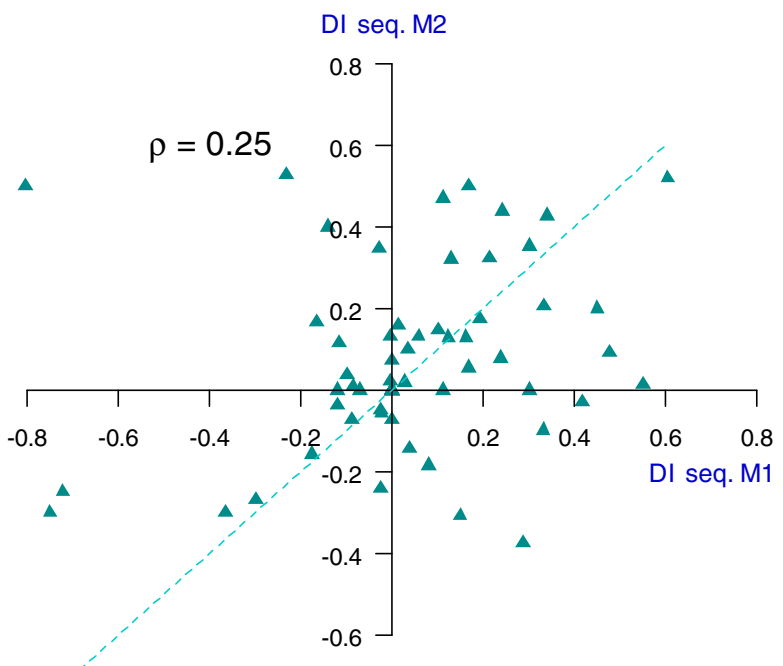

Fig. 6 DI indices for the two money sequences

exclusion of the 6 most impatient subjects: without these subjects we could reject the null hypothesis of equal hyperbolic factors in sequence $\mathrm{H} 2$ (but not in the other three sequences). While most median hyperbolic factors equaled zero, all sequences contained

A Seq. $\mathrm{H} 1$ vs seq. M1

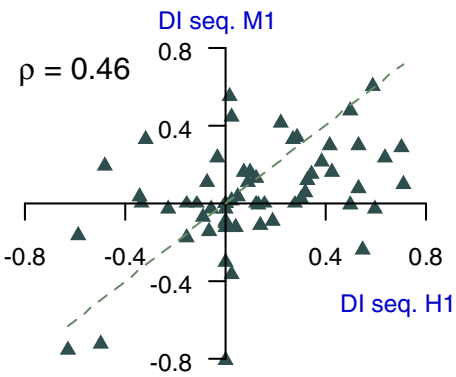

C Seq. $\mathrm{H} 1$ vs seq. M2

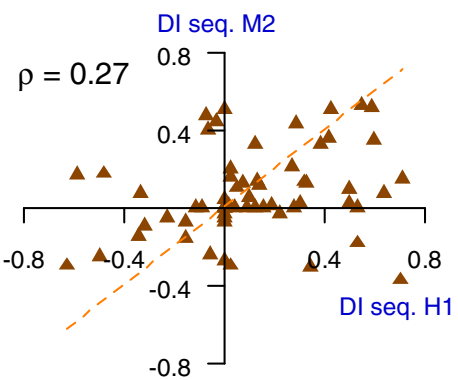

B Seq. $\mathrm{H} 2$ vs seq. M2

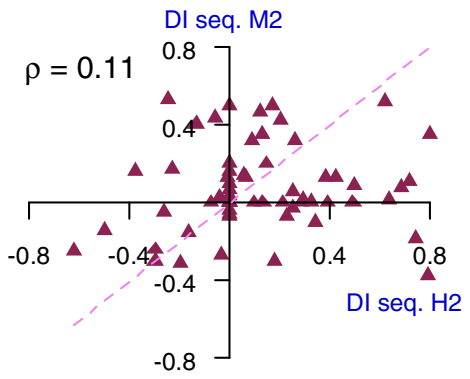

D Seq. $\mathrm{H} 2$ vs seq. M1

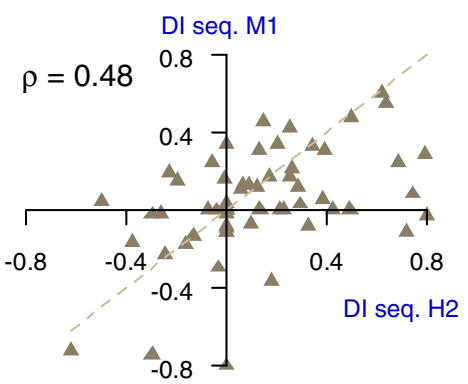

Fig. 7 DI indices for health versus money sequences 
at least one hyperbolic factor that was significantly different from 0 at the $1 \%$ significance level. This confirms, once again, that constant discounting and quasi-hyperbolic discounting did not hold. Finally, we could reject the prediction of power discounting that the hyperbolic factors equal 1 (Wilcoxon test, all $p<0.01$ ). Consequently, the only models that were consistent with our data are Loewenstein and Prelec's (1992) hyperbolic discounting and Mazur's (1987) proportional discounting, except perhaps for sequence $\mathrm{H} 2$.

\section{Discussion}

The novelty of this paper is that we quantify deviations from constant discounting across two domains: health and money. This quantification gives new insights into subjects' vulnerability to self-harming behavior and whether this vulnerability is domain-specific. Our tests make no assumptions about utility and they do not require intertemporal separability.

The main findings are as follows. First, our average subject deviated from constant discounting for both health and money and impatience decreased over time. However, time preferences were heterogeneous and a substantial minority of our subjects, between $25 \%$ and $35 \%$, displayed increasing impatience. For money, our findings on increasing impatience confirm previous evidence (e.g. Attema et al. 2010; Sayman and Öncüler 2009; Loewenstein 1987; Takeuchi 2011; Chesson and Viscusi 2003; Rubinstein 2003). For health, only indirect evidence of increasing impatience existed.

The deviations from constant discounting were more pronounced for health than for money, which indicates that people might be more vulnerable to self-control problems for health than for money. This finding also suggests that intertemporal preferences are context-dependent and that findings for money outcomes cannot be simply transferred to health. We may have found less decreasing impatience for money due to market forces. As money is tradable on financial markets and transferable across time, people's discounting of money may have been disciplined by the prevailing interest rates for money (Cubitt and Read 2007). However, we also found that time preferences were less stable for money than for health, which seems to contradict the above conjecture.

Another possible reason for the difference between discounting for health and money may be that our subjects were more familiar with decisions about money than decisions about health. Yet, one would then, again, expect that time preferences would be more stable for money than for health, in contrast to our observation. Moreover, Chapman et al. (1999) found that familiarity with medical treatments did not increase the similarity between time preferences for money and health.

Possibly, time preferences were more stable for health than for money because subjects perceived their future health as more stable than their future income. For delays up to 10 years, which we considered in our experiment, health is usually rather stable and, moreover, we instructed subjects to assume that their baseline health would remain constant to chronic back pain. However, we did not tell subjects that their income would remain constant and, as they were students, substantial changes in their income were likely in the near future (after graduation). Consequently, subjects may have realized that their future evaluation of money would change. Our analysis assumed that the evaluation of money would not change over time and this may have 
affected the estimations. For a more detailed analysis of the impact of time-dependence of utility on discounting behavior see Gerber and Rohde (2010, 2015).

Our final contribution is to obtain new evidence on the descriptive validity of discount models. Such evidence is still scarce, particularly for health. Hyperbolic discounting (Loewenstein and Prelec 1992) and proportional discounting best described intertemporal preferences, but it should be kept in mind that these two models cannot accommodate the behavior of the increasingly impatient subjects. To explain increasing impatience other discount functions are needed (Ebert and Prelec 2007; Bleichrodt et al. 2009). The widely-used quasi-hyperbolic discounting model was rejected for both money and health, casting doubt on the descriptive realism of studies that use this model to derive predictions about behavior.

Acknowledgments Arthur Attema, Peter P. Wakker, the editor W. Kip Viscusi, and an anonymous reviewer gave helpful comments on earlier versions. We acknowledge financial support from the Erasmus Research Institute of Management (ERIM). Yu Gao's research was support by a grant from the Netherlands Organisation for Scientific Research (NWO).

Open Access This article is distributed under the terms of the Creative Commons Attribution 4.0 International License (http://creativecommons.org/licenses/by/4.0/), which permits unrestricted use, distribution, and reproduction in any medium, provided you give appropriate credit to the original author(s) and the source, provide a link to the Creative Commons license, and indicate if changes were made.

\section{References}

Abdellaoui, M., Attema, A. E., \& Bleichrodt, H. (2010). Intertemporal tradeoffs for gains and losses: An experimental measurement of discounted utility. Economic Journal, 120, 845-866.

Abdellaoui, M., Bleichrodt, H., \& L'Haridon, O. (2013). Sign-dependence in intertemporal choice. Journal of Risk and Uncertainty, 47, 225-253.

Attema, A. E. (2012). Developments in time preference and their implications for medical decision making. Journal of the Operational Research Society, 63, 1388-1399.

Attema, A. E., Bleichrodt, H., Rohde, K. I. M., \& Wakker, P. P. (2010). Time-tradeoff sequences for analyzing discounting and time inconsistency. Management Science, 56, 2015-2030.

Attema, A. E., Bleichrodt, H., \& Wakker, P. P. (2012). A direct method for measuring discounting and QALYs more easily and reliably. Medical Decision Making, 32, 583-593.

Attema, A. E., Brouwer, W. B., \& l'Haridon, O. (2013). Prospect theory in the health domain: A quantitative assessment. Journal of Health Economics, 32, 1057-1065.

Bleichrodt, H., \& Johannesson, M. (2001). Time preference for health: A test of stationarity versus decreasing timing aversion. Journal of Mathematical Psychology, 45, 265-282.

Bleichrodt, H., \& Pinto, J. L. (2002). Loss aversion and scale compatibility in two-attribute trade-offs. Journal of Mathematical Psychology, 46, 315-337.

Bleichrodt, H., Rohde, K. I. M., \& Wakker, P. P. (2009). Non-hyperbolic time inconsistency. Games and Economic Behavior, 66, 27-38.

Bostic, R., Herrnstein, R. J., \& Luce, R. D. (1990). The effect on the preference reversal of using choice indifferences. Journal of Economic Behavior and Organization, 13, 193-212.

Broome, J. (1991). Weighing goods. Oxford: Basil Blackwell.

Cairns, J. A. (1992). Health, wealth and time preference. Project Appraisal, 7, 31-40.

Cairns, J. (1994). Valuing future benefits. Health Economics, 3, 221-229.

Cairns, J., \& Van der Pol, M. (1997). Constant and decreasing timing aversion for saving lives. Social Science \& Medicine, 45, 1653-1659.

Chapman, G. B. (1996). Temporal discounting and utility for health and money. Journal of Experimental Psychology: Learning Memory and Cognition, 22, 771-791.

Chapman, G. B., \& Elstein, A. S. (1995). Valuing the future: Temporal discounting of health and money. Medical Decision Making, 15, 373-386. 
Chapman, G. B., Nelson, R., \& Hier, D. B. (1999). Familiarity and time preferences: Decision making about treatments for migraine headaches and Crohn's disease. Journal of Experimental Psychology: Applied, 5, 17.

Chesson, H. W., \& Viscusi, W. K. (2003). Commonalities in time and ambiguity aversion for long-term risks. Theory and Decision, 54, 57-71.

Cropper, M. L., Aydede, S. K., \& Portney, P. R. (1994). Preferences for life saving programs: How the public discounts time and age. Journal of Risk and Uncertainty, 8, 243-265.

Cubitt, R. P., \& Read, D. (2007). Can intertemporal choice experiments elicit time preferences for consumption? Experimental Economics, 10, 369-389.

DellaVigna, S. (2009). Psychology and economics: Evidence from the field. Journal of Economic Literature, 47, 315-372.

Diamond, P., \& Köszegi, B. (2003). Quasi-hyperbolic discounting and retirement. Journal of Public Economics, 87, 1839-1872.

Ebert, J. E. J., \& Prelec, D. (2007). The fragility of time: Time-insensitivity and valuation of the near and far future. Management Science, 53, 1423-1438.

Fang, H., \& Wang, Y. (2015). Estimating dynamic discrete choice models with hyperbolic discounting, with an application to mammography decisions. International Economic Review, 56, 565-596.

Frederick, S., Loewenstein, G. F., \& O'Donoghue, T. (2002). Time discounting and time preference: A critical review. Journal of Economic Literature, 40, 351-401.

Gerber, A., \& Rohde, K. I. M. (2010). Risk and preference reversals in intertemporal choice. Journal of Economic Behavior \& Organization, 76, 654-668.

Gerber, A., \& Rohde, K. I. M. (2015). Eliciting discount functions when baseline consumption changes over time. Journal of Economic Behavior \& Organization, 116, 56-64.

Gruber, J., \& Köszegi, B. (2001). Is addiction "rational"? Theory and evidence. Quarterly Journal of Economics, 116, 1261-1303.

Gruber, J., \& Köszegi, B. (2004). Tax incidence when individuals are time-inconsistent: The case of cigarette excise taxes. Journal of Public Economics, 88, 1959-1987.

Halevy, Y. (2015). Time consistency: Stationarity and time invariance. Econometrica, 83, 335-352.

Hardisty, D.J., \& Weber, E.U. (2009). Discounting future green: Money versus the environment. Journal of Experimental Psychology: General, 138, 329.

Harvey, C. M. (1986). Value functions for infinite period planning. Management Science, 32, 1123-1139.

Harvey, C. M. (1995). Proportional discounting of future costs and benefits. Mathematics of Operations Research, 20, 381-399.

Ikeda, S., Kang, M., \& Ohtake, F. (2010). Hyperbolic discounting, the sign effect, and the body mass index. Journal of Health Economics, 29, 268-284.

Khwaja, A., Silverman, D., \& Sloan, F. (2007). Time preference, time discounting, and smoking decisions. Journal of Health Economics, 26, 927-949.

Koopmans, T. C. (1960). Stationary ordinal utility and impatience. Econometrica, 28, 287-309.

Laibson, D. (1997). Golden eggs and hyperbolic discounting. Quarterly Journal of Economics, 112, $443-477$.

Loewenstein, G. F. (1987). Anticipation and the valuation of delayed consumption. Economic Journal, 97, 666-684.

Loewenstein, G. F., \& Prelec, D. (1992). Anomalies in intertemporal choice: Evidence and an interpretation. Quarterly Journal of Economics, 107, 573-597.

Loewenstein, G. F., \& Prelec, D. (1993). Preferences for sequences of outcomes. Psychological Review, 100, 91-108.

Mazur, J.E. (1987). An adjusting procedure for studying delayed reinforcement. In M.L. Commons, J.E. Mazur, J.A. Nevin, \& H. Rachlin (Eds.), Quantitative Analyses of Behavior, 5, 55-73.

Moore, M. J., \& Viscusi, W. K. (1990). Discounting environmental health risks: New evidence and policy implications. Journal of Environmental Economics and Management, 18, S51-S62.

Newhouse, J. P. (2006). Reconsidering the moral hazard-risk avoidance tradeoff. Journal of Health Economics, 25, 1005-1014.

Phelps, E. S., \& Pollak, R. A. (1968). On second-best national savings and game-equilibrium growth. Review of Economic Studies, 35, 185-199.

Pinheiro, J., Bates, D., DebRoy, S., Sarkar, D., \& R Core Team. (2014). Nlme: Linear and nonlinear mixed effects models, Vol. R package version 3.1-117. Vienna: R Foundation for Statistical Computing.

Prelec, D. (2004). Decreasing impatience: A criterion for non-stationary time preference and 'hyperbolic' discounting. Scandinavian Journal of Economics, 106, 511-532.

R Core Team. (2013). R: A language and environment for statistical computing. Vienna: R Foundation for Statistical Computing. 
Rohde, K. I. M. (2010). The hyperbolic factor: A measure of time inconsistency. Journal of Risk and Uncertainty, 41, 125-140.

Rubinstein, A. (2003). Economics and psychology? The case of hyperbolic discounting. International Economic Review, 44, 1207-1216.

Sayman, S., \& Öncüler, A. (2009). An investigation of time-inconsistency. Management Science, 55, 470-482.

Scharff, R. L. (2009). Obesity and hyperbolic discounting: Evidence and implications. Journal of Consumer Policy, 32, 3-21.

Scholten, M., \& Read, D. (2006). Discounting by intervals: A generalized model of intertemporal choice. Management Science, 52, 1424-1436.

Strotz, R. H. (1955). Myopia and inconsistency in dynamic utility maximization. Review of Economic Studies, 23, 165-180.

Takeuchi, K. (2011). Non-parametric test of time consistency: Present bias and future bias. Games and Economic Behavior, 71, 456-478.

van der Pol, M. M., \& Cairns, J. (2002). A comparison of the discounted utility model and hyperbolic discounting models in the case of social and private intertemporal preferences for health. Journal of Economic Behavior and Organization, 49, 79-96.

van der Pol, M. M., \& Cairns, J. (2011). Descriptive validity of alternative intertemporal models for health outcomes: An axiomatic test. Health Economics, 20, 770-782.

van Osch, S. M. C., van den Hout, W. B., \& Stiggelbout, A. M. (2006). Exploring the reference point in prospect theory: Gambles for length of life. Medical Decision Making, 26, 338-346. 